\title{
Short-chain fatty acid receptor GPR43 is expressed in canine enteroendocrine $\mathbf{L}$ cells
}

\author{
J. van Baal, Y. Li, S. Groneick, W. H. Hendriks and G. Bosch \\ Animal Nutrition Group, Wageningen University, Elst 1, Wageningen, The Netherlands
}

Short-chain fatty acids (SCFA), including acetate, propionate and butyrate, are products of intestinal microbial fermentation. Apart from being absorbed as nutrients across the intestine, SCFA influence various physiological processes in the intestinal tract including intestinal motility, colonic barrier function, and secretion of the gut hormones glucagon-like peptide-1 (GLP-1) and peptide YY (PYY) (1-3). Both hormones are involved the regulation of digestive functioning and appetite ${ }^{(4)}$. In addition, SCFA could play a role in pathophysiological processes, including inflammation and colorectal carcinogenesis ${ }^{(5,6)}$. SCFA can activate the G protein-coupled receptor 43 (GPR43, also known as FFA2), which is equally sensitive to acetate, propionate, and butyrate ${ }^{(7)}$.

In this study, three adult female Beagle dogs were fed with a standard diet containing $2.4 \%$ crude fibre for at least 2 weeks. Dogs were sacrificed and digesta were collected from the duodenum, jejunum, ileum, and proximal colon for measuring SCFA concentrations. In addition, tissues of the same segments were collected for determining the cellular distribution of GPR43 by immunohistochemistry. Acetate concentration in the colon was higher than in the three small intestinal segments. Propionate and butyrate concentrations in the small intestinal segments were insignificant. Immunostaining for GPR43 was distributed in the mucosa along the whole intestine, with highest expression in the ileum. Strikingly, GPR43 expression was predominantly found in enteroendocrine L cells as these cells were also immune-positive for GLP-1 and/or PYY.

Our data suggest that in dogs acetate is the main SCFA-effector of GPR43 in the intestine and that GPR43, and thus SCFA, play a regulatory role in secretion of GLP-1 and PYY.

1. Ono S, Karaki S \& Kuwahara A (2004) Jpn J Physiol 54, 483-493.

2. Suzuki T, Yoshida S \& Hara H (2008) Br J Nutr 100, 297-305.

3. Gee JM \& Johnson IT (2005) Nutrition 21, 1036-1043.

4. Capasso A \& Izzo A (2008) J Neuroendocrinol 20, 39-46.

5. Maslowski KM \& Mackay CR (2011) Nat Immunol 12, 5-9.

6. DArgenio G, Cosenza V, Delle Cave M et al. (1996) Gastroenterology 110, 1727-1734.

7. Brown AJ, Goldsworthy SM, Barnes AA et al. (2003) J Biol Chem 278, 11312-11319. 